
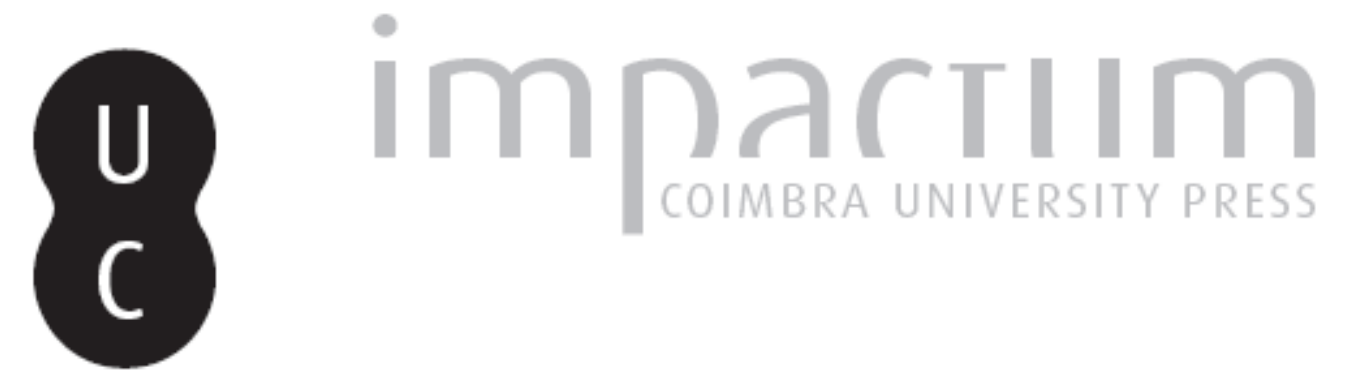

\title{
Palavras arrastadas na lírica euripidiana
}

\section{Autor(es): Lourenço, Frederico}

Publicado por: Imprensa da Universidade de Coimbra

URL persistente:

URl:http://hdl.handle.net/10316.2/34003

DOI:

DOI:http://dx.doi.org/10.14195/0872-2110_58_7

Accessed : $\quad$ 26-Apr-2023 09:13:02

A navegação consulta e descarregamento dos títulos inseridos nas Bibliotecas Digitais UC Digitalis, UC Pombalina e UC Impactum, pressupõem a aceitação plena e sem reservas dos Termos e Condições de Uso destas Bibliotecas Digitais, disponíveis em https://digitalis.uc.pt/pt-pt/termos.

Conforme exposto nos referidos Termos e Condições de Uso, o descarregamento de títulos de acesso restrito requer uma licença válida de autorização devendo o utilizador aceder ao(s) documento(s) a partir de um endereço de IP da instituição detentora da supramencionada licença.

Ao utilizador é apenas permitido o descarregamento para uso pessoal, pelo que o emprego do(s) título(s) descarregado(s) para outro fim, designadamente comercial, carece de autorização do respetivo autor ou editor da obra.

Na medida em que todas as obras da UC Digitalis se encontram protegidas pelo Código do Direito de Autor e Direitos Conexos e demais legislação aplicável, toda a cópia, parcial ou total, deste documento, nos casos em que é legalmente admitida, deverá conter ou fazer-se acompanhar por este aviso.

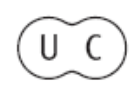


COIMBRA • 2013
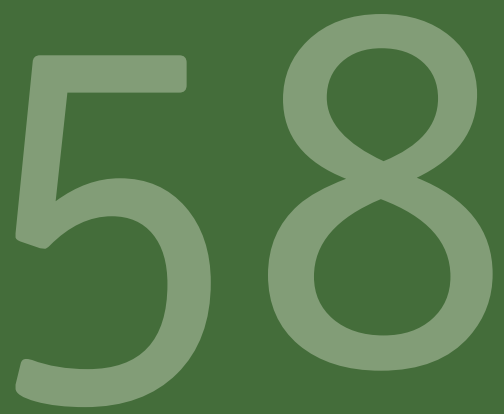

BOLETIM DE

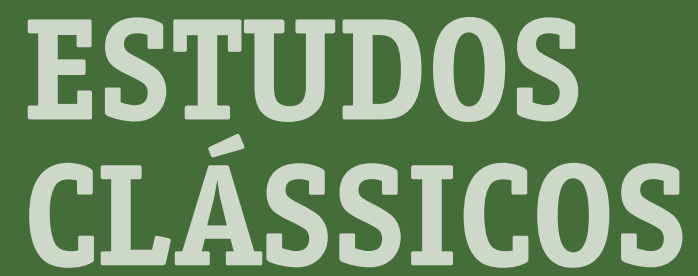

\author{
ASSOCIAÇÃO \\ PORTUGUESA \\ DE ESTUDOS \\ CLÁSSICOS \\ INSTITUTO \\ DE ESTUDOS \\ CLÁSSICOS
}




\title{
PALAVRAS “ARRASTADAS" NA LÍRICA EURIPIDIANA
}

\author{
FREDERICO LOURENÇO
}

À memória da Doutora Maria Helena Ureña Prieto, que me entusiasmou pelo estudo da métrica grega ao oferecer-me, em 1994, o seu exemplar do livro (então raríssimo) Collected Papers de A. M. Dale.

Um problema básico que se levanta no estudo da métrica grega é como partir do entendimento do ritmo para a compreensão mais aprofundada das intenções expressivas do poeta. Pois, em última análise, é de poesia que se trata - e, no caso da tragédia grega, trata-se de poesia dramática, que visa especialmente afetar o espetador-ouvinte, levando-o a reagir emotivamente às situações anímicas com que o texto poético o confronta. No registo lírico da tragédia - ou seja, nas partes cantadas pelo coro e nas monódias cantadas pelos atores - a expressividade verbal assume uma importância ainda maior. As palavras tornam-se mais plásticas, mais carregadas de potencial emotivo, também porque a variedade de recursos métricos nas secções cantadas da tragédia permite toda uma gama de efeitos que estão excluídos, à partida, das partes faladas e recitadas.

Entre esses efeitos há um que me proponho aqui exemplificar, até porque não tem sido alvo de atenção sistemática por parte dos estudiosos da tragédia grega. Trata-se de um fenómeno métrico a que, no seu livro Collected Papers, a grande especialista inglesa de métrica grega A. M. Dale define como drag ("arrastamento"), mas a que outros preferem dar a etiqueta grega $\chi \omega ́ \lambda \omega \sigma \mathfrak{~}$ (em português "colose") $)^{1}$ "Arrastar"

1 Cf. Dale (1969: 67), Maas (1962), West (1982: 194). Para um glossário explicativo da 
deverá entender-se, aqui, no sentido de desacelerar, abrandar; em termos musicais, falar-se-ia de rallentando - como, de resto, faz Dale em The Lyric Metres of Greek Drama (pp. 10,117), livro ainda hoje imprescindível para o estudo do que nos restou da música do teatro grego: o ritmo.

Do ponto de vista métrico, no que consiste este fenómeno? Consiste simplesmente na presença de uma sílaba longa numa posição onde o esquema do verso exigiria (ou, pelo menos, faria prever) uma sílaba breve. Tão simples quanto isso. Ora, no tocante a este fenómeno, interessar-nos-á essencialmente o seu potencial expressivo, que iremos surpreender nalguns exemplos tirados de versos cantados desse superlativamente expressivo autor de poesia lírica que foi Eurípides. É que "o mais trágico dos poetas" não se socorre desta possibilidade métrica enquanto mera licença ou liberdade, apenas para não abdicar de palavras cuja prosódia arrevesada cria dificuldades de integração no verso. Socorre-se dela (eu diria na maior parte dos casos) com deliberado intuito expressivo, para salientar a palavra em questão, para lhe dar um relevo especial no contexto não só do verso, mas também muitas vezes no contexto da estância no seu todo. Estas palavras "arrastadas", estas dragged words, são também palavras iluminadas, no sentido de highlighted words. Trata-se de lhes conferir ênfase, de as sublinhar e de as pôr em relevo.

Em tal contexto, o jogo de contraste entre sílabas breves e longas é, evidentemente, essencial. Isto porque podemos constatar que, numa sequência só de sílabas breves ou numa sequência só de sílabas longas, difícil é entender-se que o poeta queira destacar alguma palavra em especial. Quando, no v. 220 da Ifigénia entre os Tauros, a protagonista diz

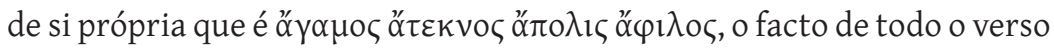
ser constituído por sílabas breves impede que uma palavra em particular se destaque das demais: o sentido será, antes, e deliberadamente, não destacar nenhuma das quatro palavras. Por outro lado, quando o Frígio no v. 1496 do Orestes invoca, num verso constituído somente por

terminologia métrica em português, cf. Lourenço (2011a). 


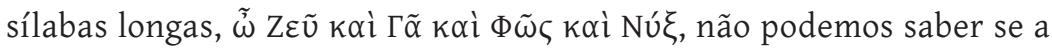
entidade que se destaca mais da invocação é Zeus, a Terra, a Luz ou a Noite. No entanto, quando a Jocasta das Fenícias se dirige ao filho em canto arrebatado, exprimindo quão desejada era a sua presença para os amigos e para Tebas, há um sublinhar claro da palavra Tebas (vv. 320-1):

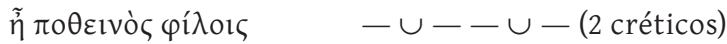

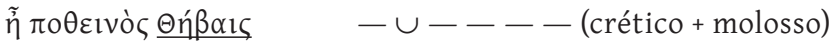

Não foi só à família e aos amigos que Polinices deixou saudades; sobretudo a cidade de Tebas sente falta dele. A métrica salienta claramente o nome da cidade, defraudando a expetativa de um quarto crético. Ao molosso (_- - ) cabe, pois, uma missão de expressividade, que a oralização do verso confirma.

O jogo de contraste entre longas e breves só é possível quando o esquema métrico foge à previsibilidade. Por exemplo, em contexto de anapestos mélicos (= cantados), é muito frequente depararmo-nos com versos inteiramente constituídos por sílabas longas. Onde as sílabas longas predominam, uma palavra que configure mais uma sequência de longas não adquire destaque. Por isso não recai nenhuma forma de ênfase sobre o nome K $\alpha \sigma \sigma a ́ v \delta \delta \rho \alpha$ no v. 88 da Hécuba, já que o contexto é anapéstico e sílabas longas a fio não faltam. Diferente é a situação no v. 248 das Troianas, onde parece claro que Eurípides quer pôr em relevo o nome da princesa troiana:

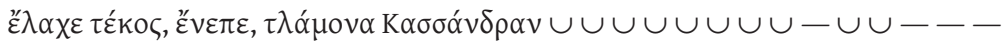

As três sílabas longas, que são a forma métrica do nome "Cassandra", adquirem aqui especial destaque, precedidas por uma sequência predominantemente constituída por sílabas breves. A forma do verso também é, aqui, relevante. Tratando-se de dócmios, a forma mais canónica e mais utilizada é $\cup--\cup-$, ou seja, com uma sílaba breve na penúltima posição. $\mathrm{O}$ nome de Cassandra leva a que tenhamos um 
dócmio com desfecho arrastado (dragged close, na terminologia de Dale), o que confere à oralização do verso um efeito de rallentando. É justo, porém, frisar que esse efeito de rallentando expressivo nos dócmios é frequentemente utilizado pelos três tragediógrafos, também pelo facto de o ritmo docmíaco, na sua flexibilidade e subtileza de adaptação ao sentido do texto, constituir o campo mais variado de expressividade lírica na tragédia grega.

Em contexto eólico, este tipo de expressividade é mais difícil de materializar. No entanto, Eurípides - de resto o único dos três trágicos que se aventura a tal coisa em ritmo eólico - consegue, por vezes, extrair do efeito surpresa da quantidade inesperada um enfoque expressivo apontado para uma palavra específica. Exemplificando: se pensarmos que o esquema regular do glicónico é, com raríssimas exceções², oo $-\cup \cup-\cup-$, há inegavelmente um efeito de surpresa que é criado por um glicónico arrastado, a terminar em -- , em vez de em $\cup-$. 124 Assim, na Electra de Eurípides, a filha de Clitemnestra consegue dar uma ênfase especial ao nome terrível da mãe na sua monódia por meio do efeito de arrastamento no glicónico. o glicónico arrastado destaca-se ainda mais pelo facto de estar ladeado de glicónicos normais, com a penúltima sílaba breve (El. 115-9):

\begin{tabular}{|c|c|c|}
\hline 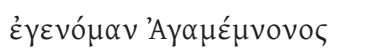 & $\cup \cup \cup-\cup \cup-\cup-$ & glicónico \\
\hline 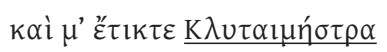 & $-\cup-\cup \cup---$ & gl arrastado \\
\hline 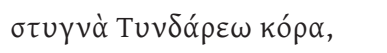 & $---\cup \cup-\cup-$ & gl \\
\hline 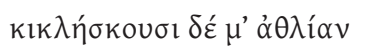 & $\cup--\cup \cup-\cup-$ & $\mathrm{gl}$ \\
\hline 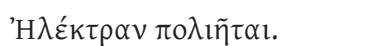 & $---\cup \cup--$ & ferecrácio \\
\hline
\end{tabular}

Estes versos são curiosos no sentido em que patenteiam quatro nomes próprios: Agamémnon, Clitemnestra, Tindáreo e Electra. É significativo

2 Cf. Lourenço (2011b: 93-4). 
que, dos quatro, o nome que "viola" a métrica e não é suscetível de ser enquadrado num verso éolico "normal" é o de Clitemnestra.

Em 1997, a maior especialista atual de métrica grega, Laetitia Parker, publicou um importante ensaio com o sugestivo título "Ce qui nous manque: mètre et effet dramatique chez Aristophane". Espero com estes breves apontamentos ter contribuído para dar um passo na mesma direção, desta feita no tocante a Eurípides.

\section{BIBLIOGRAFIA}

DALE, A. M. (1968²), The Lyric Metres of Greek Drama, Cambridge.

- (1969), Collected Papers, Cambridge.

LOURENÇO, F. (2011a), "Para uma terminologia portuguesa da métrica grega", Boletim de Estudos Clássicos 55, pp. 15-27.

- (2011b), The Lyric Metres of Euripidean Drama, Coimbra.

MAAS, P. (1962), Greek Metre, 1962.

PARKER, L. P. E, (1997), "Ce qui nous manque: mètre et effet dramatique chez Aristophane”, in P. Thiercy (ed.), Aristophane: La Langue, La Scène, La Cité, Bari, pp. 75-85.

WEST, M. L. (1982), Greek Metre, Oxford. 